\title{
Akulturasi Budaya Bugis dengan Islam dalam Tradisi Barzanji di Sulawesi Selatan
}

\author{
Dian Rizki Amalia \\ Departement of Antropology Education, Faculty of Social Science and Law, \\ Universitas Negeri Makassar, Indonesia \\ E-mail: dianrski342@gmail.com
}

\begin{abstract}
This writing aims to find out the customs that exist in the region of South Sulawesi. Barzanji is a tradition found in the region of South Sulawesi (bugis -Makassar) barzanji is a prayer or praise of the story of the Prophet Muhammad, where there is a rhythm or melody that is sung at the birth of the Prophet Muhammad. Barzanji hails from a place in Kurdistan that was set up to increase love for the Prophet Muhammad Saw and also as a form of Islamic acculturation to unify local customs. This tradition is still widely practiced in Makassar because it has many meanings. The type of research used in this writing is qualitative descriptive by using library research methods and looking for other sources and to consolidate and clarify the results of observations.
\end{abstract}

Keywords: meaning, barzanji, tradition, history.

\section{References}

Abdullah, Ahmad Mujahid. 2012. "(The Practice of Barzanji, Is It in Line with Islamic Teaching? Amalan Berzanji, Adakah Ia Selaras Dengan Ajaran Islam?” Jurnal Antarabangsa Kajian Asia Barat 4(2): $23-35$.

Ahmadin, S. A. (2020). Sejarah Peradaban Islam. Prenada Media.

ARIFIN, Andi Siska Putri Utami; RAHMAN, Abdul. Mabbaca Doang di Pasaka Bone. Jurnal Kajian Sosial dan Budaya: Tebar Science, [S.1.], v. 3, n. 2, p. 101-112, June 2019.

Eljinand, Rayhand. 2020. "Kata Kunci Value Education, Morality, Barzanji Book." 6(1): 35-60.

Faizal, Moh. 2019. “Jurnal Al-Makrifat Vol 4, No 2, Oktober 2019.” : 56-69.

Fattah, Abdul, Universitas Negeri Malang, Lutfiah Ayundasari, and Universitas Negeri Malang. 2021a. "Mabbarazanji: Tradisi Membaca Kitab Barzanji Dalam Upaya Meneladani Kehidupan Nabi." 7(1): 49-60.

. 2021b. "Mabbarazanji: Tradisi Membaca Kitab Barzanji dalam Upaya Meneladani Kehidupan Nabi." 7(1): 49-60.

Hamid, Idham. "Tradisi Barzanji , Antara Sakral dan Profan Di Masjid Raya Campalagian." 
Jubba, Hasse, Ahmad Sultra Rustan, and Juhansar Juhansar. 2018. "Kompromi Islam Dan Adat Pada Praktik Keagamaan Muslim Bugis Di Sulawesi Selatan.” JSW (Jurnal Sosiologi Walisongo) 2(2): $137-48$.

Mirnawati, Mirnawati. 2019. “Analisis Semiotika Dalam Teks Al-Barzanji.” ‘A Jamiy: Jurnal Bahasa dan Sastra Arab 8(1): 31.

Muttaqin, Ahmad. 2016. “'Barzanji Bugis’ Dalam Peringatan Maulid: Studi Living Hadis Di Masyarakat Bugis, Soppeng, Sul-Sel.” Jurnal Living Hadis 1(1): 129.

Politik, Jurusan, and Fisipol Ugm. "TRADISI , SUNNAH \& BID ' AH: Analisa Barzanji Dalam Perspektif Cultural Studies." 14(2): 226-42.

Ta, Ahmad. 2009. "Tafsir Budaya Atas Tradisi." (9): 1-14.

Wekke, Ismail Suardi. 2013. "Islam dan Adat: Tinjauan Akulturasi Budaya Dan Agama Bugis." Analisis 13(1): 48. 